\title{
Surgery of the chest wall: indications, timing and technical aspects
}

Chest wall resection and reconstruction represent a major challenge for thoracic surgeons, both in neoplastic or non-neoplastic settings. Although many advances have been made since Clagett first reported his pioneering experience about chest wall resections for primary tumors (1), many technical aspects are still widely debated and several different techniques have been described during the years (2).

Direct infiltration of the chest wall by breast cancer or pulmonary tumors still represent the most common indication for this procedure, while primary chest wall tumors—originating from soft tissue or bones or cartilages—represent less than $30 \%$ of the indications $(3,4)$. Non oncologic indications are usually represented by congenital disorders, inflammatory and infectious diseases like abscesses, osteomyelitis or traumas. In some scenarios, chest wall resection may play a palliative role for controlling ulcerated and infected cancers as well as painful lesions already treated by radiotherapy, thus representing a salvage approach to not otherwise treatable conditions. In this particular setting-as well as in case of complex demolition and challenging reconstruction-a multidisciplinary approach is of paramount importance, involving thoracic and plastic surgeons, radiotherapists, oncologists, anesthesiologists and physiotherapists $(5,6)$.

Chest wall resection usually requires the removal of a full-thickness portion of the chest wall, including muscle, bones, and-in some cases—-skin; however lesser resection may be indicated in selected cases $(7,8)$.

Modern prosthetic materials offer excellent chances for replacing resected tissues, even in case of very extended resections; on the contrary, despite the progress of surgical techniques and prosthetic materials, several major complications-in particular respiratory complications_-are still reported and surgeons dealing with this kind of surgery should be familiar with their management $(9,10)$.

We felt the need to lead a special issue on this topic because it represents the ideal mix of technical skills, oncologic and pathophysiologic competences as well as one of the most intriguing aspects of thoracic surgery.

The variety of reconstruction techniques, the biomaterials and prosthetic devices represent only some topic to be debated, in particular nowadays with 3D printing and stem cell technology evolution.

In the light of the heterogeneous surgical skills required by this procedure and the wide spectrum of treated lesions, we are glad to lead this special issue of the "Fournal of Thoracic Disease" and we thank all the colleagues who accepted our invitation to create an effective support to the clinical practice of all the surgeons facing with this challenging surgery.

\section{Acknowledgments}

None.

\section{Footnote}

Conflicts of Interest: The authors have no conflicts of interest to declare.

Ethical Statement: The authors are accountable for all aspects of the work ensuring that questions related to the accuracy or integrity of all parts of the work are appropriately investigated and resolved.

\section{References}

1. Pascuzzi CA, Dahlin DC, Clagett OT. Primary tumors of the ribs and sternum. Surg Gynecol Obstet 1957;104:390-400.

2. Ferraro P, Cugno S, Liberman M, et al. Principles of chest wall resection and reconstruction. Thorac Surg Clin 2010;20:465-73.

3. Mansour KA, Thourani VH, Losken A, et al. Chest wall resections and reconstruction: a 25-year experience. Ann Thorac Surg 2002;73:1720-5; discussion 1725-6. 
4. Weyant MJ, Bains MS, Venkatraman E, et al. Results of chest wall resection and reconstruction with and without rigid prosthesis. Ann Thorac Surg 2006;81:279-85.

5. Spaggiari L, Galetta D, Veronesi G, et al. Superior vena cava replacement for lung cancer using a heterologous (bovine) prosthesis: preliminary results. J Thorac Cardiovasc Surg 2006;131:490-1.

6. Arnold PG, Pairolero PC. Chest wall reconstruction: an account of 500 consecutive patients. Plast Reconstr Surg 1996;98:804-10.

7. Hazel K, Weyant MJ. Chest Wall Resection and Reconstruction: Management of Complications. Thorac Surg Clin 2015;25:517-21.

8. Petrella F, Radice D, Borri A, et al. Chest wall resection and reconstruction for locally recurrent breast cancer: From technical aspects to biological assessment. Surgeon 2016;14:26-32.

9. Deschamps C, Tirnaksiz BM, Darbandi R, et al. Early and long-term results of prosthetic chest wall reconstruction. J Thorac Cardiovasc Surg 1999;117:588-91; discussion 591-2.

10. Spaggiari L, Tessitore A, Casiraghi M, et al. Survival after extended resection for mediastinal advanced lung cancer: lessons learned on 167 consecutive cases Ann Thorac Surg 2013;95:1717-25.

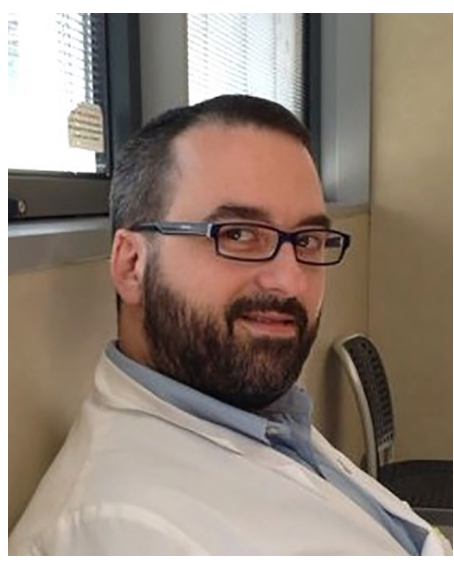

Francesco Petrella

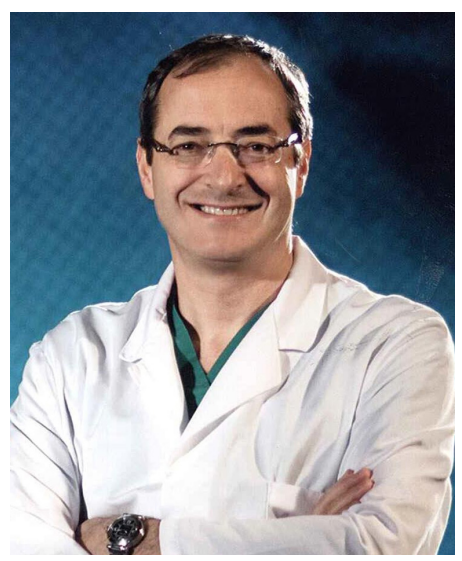

Lorenzo Spaggiari

Francesco Petrella, $\mathrm{MD}, \mathrm{PhD}^{1,2}$ (Email: francesco.petrella@ieo.it; francesco.petrella@unimi.it)

Lorenzo Spaggiari, $\mathbf{M D}, \mathbf{P h D}^{1,2}$ (Email: lorenzo.spaggiari@ieo.it) ${ }^{1}$ Department of Thoracic Surgery, IRCCS European Institute of Oncology, Milan, Italy; ${ }^{2}$ Department of Oncology and Hemato-oncology, University of Milan, Milan, Italy. doi: $10.21037 /$ jtd.2019.10.20

View this article at: http://dx.doi.org/10.21037/jtd.2019.10.20
Cite this article as: Petrella F, Spaggiari L. Surgery of the chest wall: indications, timing and technical aspects. J Thorac Dis 2020;12(1):1-2. doi: 10.21037/jtd.2019.10.20 